\title{
A estação ferroviária de Paracambi: mudanças e permanências econômicas no Extremo Oeste Metropolitano Fluminense
}

La estación de ferrocarril de Paracambi: cambios y permanencias económicas en el Extremo Oeste Metropolitano Fluminense

Paracambi's railway station: economic changes and continuities in the Far West Metropolitan of Rio de Janeiro

La gare de Paracambi: changes et permanences économiques à l'Extreme Ouest Metropolitain du Rio de Janeiro

\section{Zilmar Luiz dos Reis Agostinho}

\section{OpenEdition}

Journals

\section{Edição electrónica}

URL: http://journals.openedition.org/espacoeconomia/16738

DOI: 10.4000/espacoeconomia. 16738

ISSN: 2317-7837

\section{Editora}

Núcleo de Pesquisa Espaço \& Economia

Refêrencia eletrónica

Zilmar Luiz dos Reis Agostinho, «A estação ferroviária de Paracambi: mudanças e permanências econômicas no Extremo Oeste Metropolitano Fluminense », Espaço e Economia [Online], 19 | 2020, posto online no dia 01 setembro 2020, consultado o 10 setembro 2020. URL : http:// journals.openedition.org/espacoeconomia/16738; DOI : https://doi.org/10.4000/espacoeconomia 16738

Este documento foi criado de forma automática no dia 10 setembro 2020.

(c) NUPEE 


\section{A estação ferroviária de Paracambi: mudanças e permanências econômicas no Extremo Oeste Metropolitano Fluminense}

La estación de ferrocarril de Paracambi: cambios y permanencias económicas en el Extremo Oeste Metropolitano Fluminense

Paracambi's railway station: economic changes and continuities in the Far West Metropolitan of Rio de Janeiro

La gare de Paracambi: changes et permanences économiques à l'Extreme Ouest Metropolitain du Rio de Janeiro

\section{Zilmar Luiz dos Reis Agostinho}

1 Ao levarmos em conta que a Geografia é uma ciência que analisa, entre outras incumbências, os objetos que se fazem presentes em uma determinada paisagem, buscando estabelecer as suas relações com outros elementos do espaço geográfico, não é das tarefas mais fáceis escrever acerca do desenvolvimento histórico de um determinado objeto sob a ótica geográfica. Portanto, ao decidirmos utilizar como objeto de estudo uma estação ferroviária que se faz presente na paisagem de um município que se encontra no extremo oeste da Região Metropolitana do Rio de Janeiro, temos que ter em mente que ela passou por algumas etapas ao longo do tempo, que eram o presente daquela época, mas que hoje se encontram no passado. Embora buscar explicações geográficas incluindo-se uma noção de tempo já não seja mais uma novidade - houve um progresso considerável nesse sentido a partir das décadas de 1960 e 1970 -, tal busca continua sendo um tanto quanto tortuosa para os geógrafos, como nos diz Milton Santos:

A geografia histórica pretende retraçar o passado, mas ela o faz assentada no presente, isto é, a partir do momento em que é escrita. Em que medida ela pode revelar o que arbitrariamente se chama de passado, quando, em vez de mostrar a 
coerência simultaneamente espacial e temporal de um mesmo momento, apenas reúne instantes disparatados e distantes da mesma flecha do tempo? Enfrentamos, aqui, o difícil problema de discernir, através de uma geografia retrospectiva, o que, num dado ponto do passado, era, então, presente (SANTOS, 2004; 1996, p.51).

Portanto, ao tentarmos compreender a estação ferroviária de Paracambi como um objeto fundamental para a manutenção de um modelo econômico que estava profundamente assentado sobre uma base escrava e que, pouco tempo depois, teve papel decisivo para um incipiente modelo industrial (que ainda convivia com o modelo escravocrata), temos que ter em mente que tais momentos nada mais eram do que reflexos do espaço geográfico do século XIX e que tais objetos transformaram-se e/ou mudaram de função ao longo do tempo, indo, no caso da estação paracambiense, desde um local que servia como escoadouro da produção cafeeira do Vale do Paraíba fluminense, passando também a servir à indústria têxtil, até chegar ao seu uso atual que é o de transportar passageiros em direção aos demais municípios da Baixada Fluminense e ao Rio de Janeiro.

O passado passou, e só o presente real, mas a atualidade do espaço tem isto de singular: ela é formada de momentos que foram, estando agora cristalizados como objetos geográficos atuais; essas formas-objetos, tempo passado, são igualmente tempo presente enquanto formas que abrigam uma essência, dada pelo fracionamento da sociedade total. Por isso, o momento passado está morto como tempo, não porém como espaço [...] (SANTOS, 2004; 1982, p.14).

3 Sendo assim, a estação ferroviária de Paracambi é um objeto que se apresenta diante de nós no tempo e no espaço ou, de acordo com as palavras do autor supracitado, na dupla dimensão da atualidade. Contudo, embora tenha sido idealizada e construída sob uma lógica do passado, apresentando uma essência deste tempo passado, ela está concretizada como um objeto geográfico atual.

O objetivo do presente artigo, portanto, é compreender a importância da estação ferroviária de Paracambi como objeto fundamental para o modelo econômico baseado na escravidão, principalmente no que diz respeito ao escoamento da produção cafeeira do Vale do Paraíba fluminense. Além disso, buscamos também analisar a presença da ferrovia como fator primordial para a chegada da Companhia Têxtil Brasil Industrial na futura Paracambi, ainda que isso não significasse uma mudança definitiva de um modelo econômico agrícola e escravocrata para um modelo urbano-industrial.

Para alcançarmos nosso objetivo, buscamos, primeiramente, traçar um breve histórico da formação do atual município de Paracambi, desde o século XVIII até 1960, quando houve a emancipação a partir de terras desmembradas de distritos pertencentes ao município de Itaguaí e também ao município de Vassouras. Após essa breve exposição, analisaremos os debates e as pressões exercidas pelas elites cafeicultoras para que a ferrovia fosse instalada em Paracambi, encontrando um meio mais efetivo e lucrativo para o escoamento da produção cafeeira. No entanto, pouco depois da chegada da estação ferroviária ao então povoado de Macacos, a produção cafeeira no Vale do Paraíba fluminense começava a dar sinais de crise, sobretudo devido à forma como os grandes proprietários de terras lidavam com o solo, causando seu empobrecimento, além da escassez e do consequente encarecimento da mão de obra escrava, levando muitos cafeicultores a contraírem dívidas que se tornaram impagáveis. É nesse cenário que passamos ao último ponto de nosso texto que diz respeito ao debate sobre os motivos que levaram à escolha do povoado de Macacos para a instalação de uma fábrica têxtil em um país que ainda estava economicamente alicerçado no modelo 
escravocrata, além de analisarmos a importância da Companhia Têxtil Brasil Industrial para a dinâmica social de Paracambi.

Conforme dissemos, o município de Paracambi faz parte da Região Metropolitana do Rio de Janeiro, estando distante $81 \mathrm{~km}$ da capital fluminense, ligando-se a ela pela Rodovia Presidente Dutra, além de uma linha de ônibus e pela ferrovia atualmente administrada pela empresa SuperVia S.A. Paracambi apresenta uma área total de $190,949 \mathrm{~km}^{2}$ e uma população estimada (2019) segundo o Instituto Brasileiro de Geografia e Estatística (IBGE) ${ }^{1}$ de 52.257 habitantes, tendo como municípios limítrofes Mendes, Engenheiro Paulo de Frontin, Piraí, Miguel Pereira, Itaguaí, Seropédica e Japeri. Por estar situado na borda da Região Metropolitana, o município de Paracambi (indicado pela seta vermelha) limita-se com a Região do Médio Paraíba e também com a Região Centro-Sul, a quem está historicamente ligado, além de fazer parte da chamada Baixada Fluminense.

Figura 1 - Região Metropolitana do Rio de Janeiro (2018) ${ }^{2}$

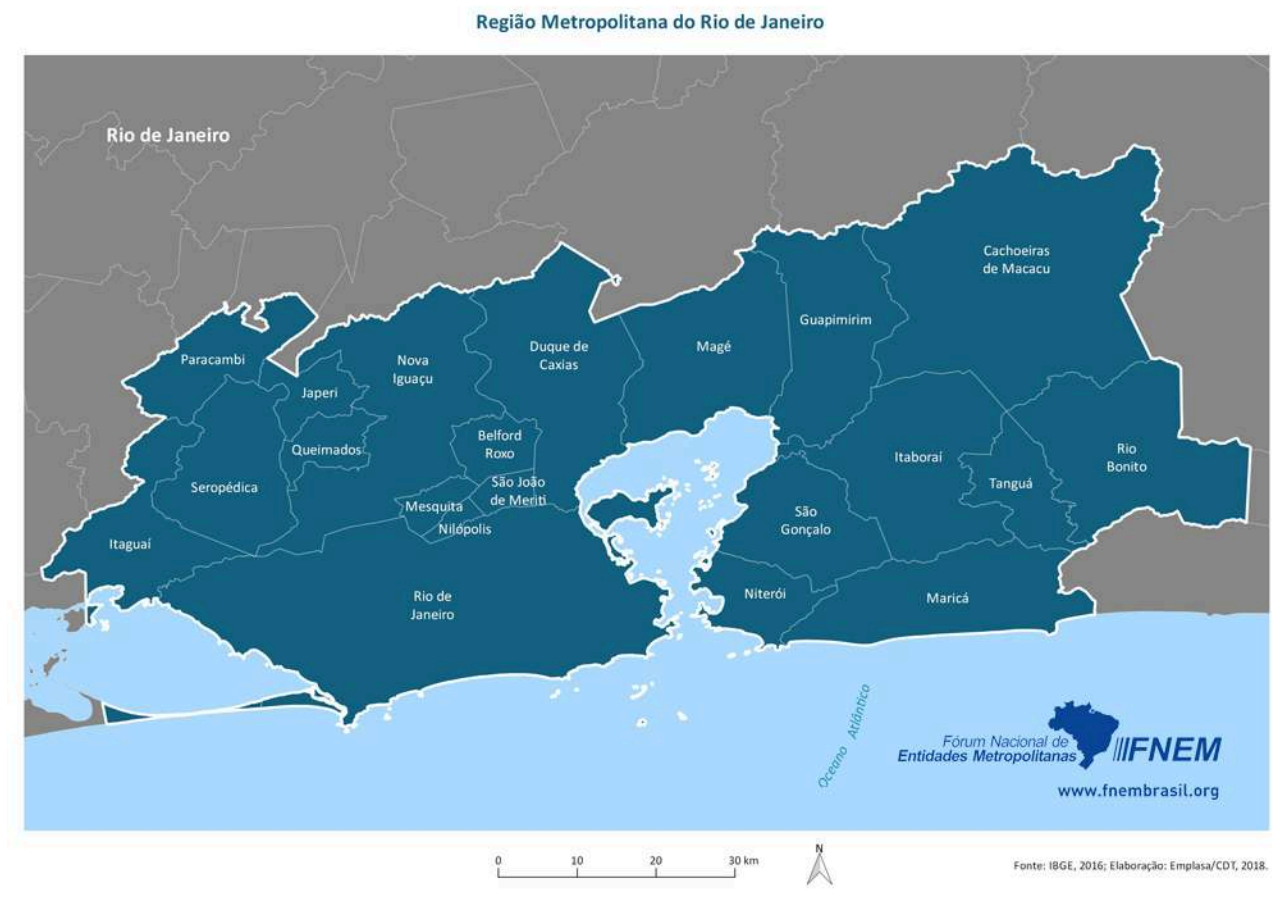

Fonte : IBGE, 2016

7 Além da estação localizada no atual centro da cidade de Paracambi, há outra estação, também administrada pela SuperVia S.A., localizada em Lages, inaugurada antes mesmo da estação de Macacos, já em 1858. No diagrama abaixo, podemos observar que o sistema ferroviário metropolitano atual, administrado pela citada empresa, é composto por oito ramais (Deodoro, Santa Cruz, Japeri, Paracambi, Belford Roxo, Saracuruna, Vila Inhomirim e Guapimirim), além do teleférico que serve ao Complexo do Alemão. Para se chegar a Paracambi (ramal em azul no diagrama) a partir da atual Central do Brasil, o usuário da ferrovia terá que percorrer um total de trinta e três estações, necessariamente fazendo a baldeação na estação de Japeri para o ramal que leva a Paracambi, composto por apenas duas estações (Lages e Paracambi), em um caminho que, para ser totalmente percorrido, leva cerca de uma hora e cinquenta minutos, sem contar o tempo de espera na baldeação. 
Figura 2 - Diagrama de rede da SuperVia S.A. ${ }^{3}$

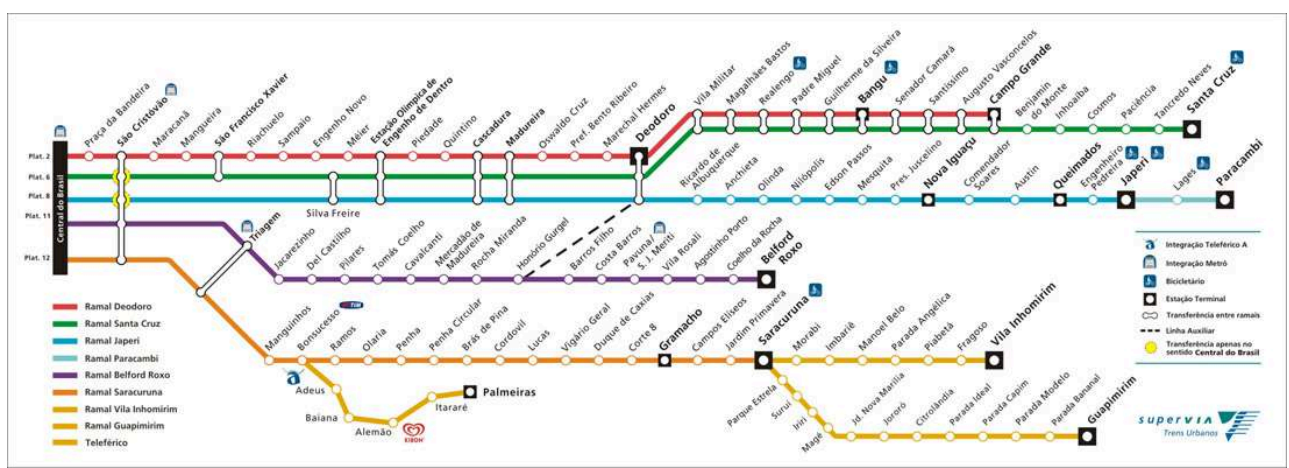

Fonte : Supervia Trens Urbanos

Importante apontar que entre as estações de Japeri e a estação de Lages, funcionou, até 2012, a estação Doutor Eiras (1964), que teve as suas atividades encerradas devido ao fechamento do hospital psiquiátrico homônimo situado em frente. Outras estações existiram ou atualmente encontram-se desativadas no território do atual município de Paracambi em direção à serra com destino a Vassouras, tais como, a estação de Guedes da Costa (1863), anteriormente chamada de Bifurcação, pois era dela que saía o ramal de Paracambi; Elisson (1917); Mário Bello (1878), antiga Oriente, que funcionou até 1996, atendendo ao transporte de passageiros entre Japeri e Barra do Piraí; e Engenheiro Gurgel (1878), antiga Serra, que foi demolida. No mapa abaixo, observamos as estações citadas - cujo trecho encontra-se apontado pela seta azul - que ainda se encontravam em funcionamento no ano de 1928.

Outra importante observação a se fazer no mapa abaixo é que a atuais estações de Comendador Soares, Engenheiro Pedreira e Japeri ainda conservavam seus antigos nomes: Morro Agudo, Caramujos e Belém, respectivamente. Além disso, pode-se observar que a bifurcação entre Japeri (Belém) e Paracambi acontecia realmente em Guedes da Costa. 
Figura 3 - Linha do Centro e da Linha Auxiliar (1928) ${ }^{4}$

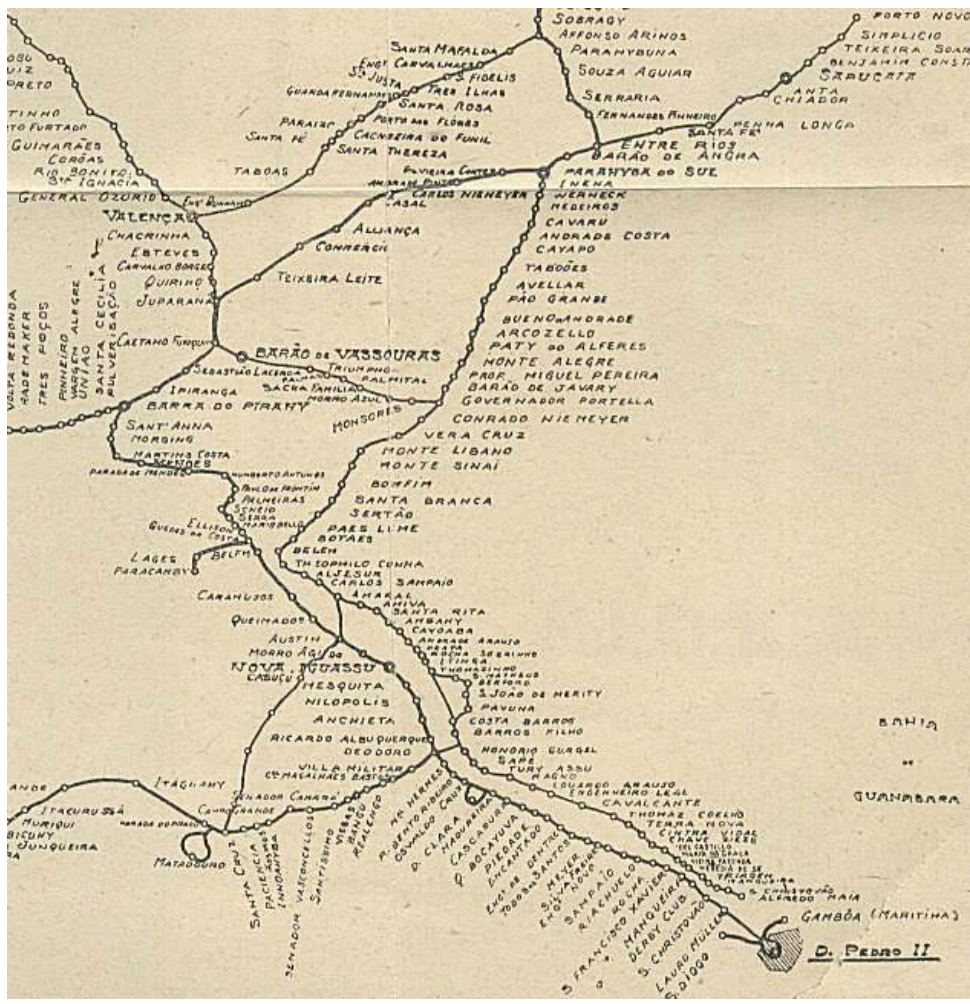

Fonte: www.estacoesferroviarias.com.br.

10 Devemos ter em mente também que, embora cobrindo um trecho bastante curto, de aproximadamente oito quilômetros até Japeri, a chegada da linha férrea ao atual município de Paracambi foi consequência de pressões e disputas entre grandes cafeicultores desejosos por uma maneira mais rápida e lucrativa para o escoamento da produção.

\section{Formação histórica do município}

O atual município de Paracambi apresenta a particularidade de ter sido formado a partir de dois distritos pertencentes a dois municípios diferentes: Paracambi, o terceiro distrito de Itaguaí; e Tairetá, o sétimo distrito de Vassouras.

Entretanto, a formação histórica de Paracambi remonta ao século XVIII, quando os jesuítas ocuparam parte das terras pertencentes à antiga Fazenda Real de Santa Cruz (depois Fazenda Imperial de Santa Cruz), construindo uma igreja dedicada a São Francisco Xavier e que foi concluída em 1729. Por meio de uma Ordem Régia datada de 22 de dezembro de 1795, a localidade passa a se configurar como uma Freguesia subordinada ao Rio de Janeiro e a Angra dos Reis, recebendo o nome de São Francisco Xavier de Itaguaí. Através de aforamentos, arrendamentos e outros tipos de autorizações posteriores, as terras da Fazenda passaram a ser ocupadas por agricultores e pecuaristas.

13 Já no século XIX, a Freguesia de São Francisco Xavier de Itaguaí passa à categoria de Vila através do alvará datado de 05 de junho de 1818. Em virtude da Lei Provincial nº 77, de 29 de dezembro de 1836, é criada a Freguesia de São Pedro e São Paulo do Ribeirão 
das Lages, sendo uma das três freguesias que compunham a Vila de São Francisco Xavier de Itaguaí, juntamente com a sede e Nossa Senhora da Conceição do Bananal e que, segundo Oliveira (2015) diferenciavam-se pelo tipo de cultura realizada pelos fazendeiros presentes nessas localidades. Destacavam-se na Freguesia de São Pedro e São Paulo do Ribeirão das Lages as fazendas dos Bravos, Anta Soares, Viúva Jorge e dos Macacos. Na área onde se localizava a Fazenda dos Macacos existia o povoado do Ribeirão dos Macacos que, de acordo com o Instituto Brasileiro de Geografia e Estatística (IBGE), era um caminho obrigatório para São Paulo e Minas Gerais. Seria nas terras pertencentes à Fazenda dos Macacos que, futuramente, haveria a instalação da Companhia Têxtil Brasil Industrial. A então freguesia era a maior produtora de café em Itaguaí nos anos 1850 , tendo perdido boa parte de suas terras com a criação da Freguesia de Nossa Senhora da Conceição do Bananal.

14 Ainda de acordo com o IBGE, por força do Decreto Estadual n.S 1 de 08 de maio de 1892, a localidade de São Pedro e São Paulo do Ribeirão das Lages foi elevada a condição de distrito, ligado politicamente ao município de Itaguaí. Já a Lei Estadual n.201 de 06 de dezembro de 1895 alterou o nome do distrito de São Pedro e São Paulo do Ribeirão das Lages para Macacos, ainda pertencente a Itaguaí, tendo novamente seu nome trocado de Macacos para Paracambi pela Lei Estadual n.536 de 19 de dezembro de 1901. Por outro lado, a Lei Estadual n.881 de 11 de setembro de 1909 criou o distrito de Belém, anexado ao município de Vassouras. A Lei Estadual n.1619 de 06 de novembro de 1919 alterou o nome do distrito de Belém para Paracambi. Portanto, podemos perceber que a partir de 1919, havia dois distritos com o nome de Paracambi, sendo um (ex-Macacos) pertencente a Itaguaí e outro (ex-Belém) pertencente a Vassouras, separados apenas pelo Rio dos Macacos. Importante salientar que

a parte que envolvia o atual centro e que se estendia até a estação ferroviária, denominada Macacos, fazia parte do $7^{\circ}$ Distrito de Vassouras. A partir do rio até as instalações da Fábrica Brasil pertencia ao 3ํㅡㄹ Distrito de Itaguaí (PEREIRA, 2018, p. 35).

O fato de haver dois distritos com o mesmo nome perdurou até 1938, quando o Decreto n.641 de 15 de dezembro mudou o nome do distrito vassourense de Paracambi para Tairetá. Por fim, a Lei Estadual n.4426 de 08 de agosto de 1960 desmembrou o $3^{\text {o }}$ distrito de Itaguaí (Paracambi) e o $7^{\circ}$ distrito de Vassouras (Tairetá) que passaram a formar o município de Paracambi, haja vista que, a população de ambos os distritos faziam parte de uma mesma dinâmica social.

Elencar todas essas leis e decretos é fundamental para que possamos compreender a complexidade da formação histórica e legal do município de Paracambi, bem como facilitar a compreensão do leitor quanto a possíveis confusões que possam surgir em virtude das coincidências de nomes.

\section{A chegada da ferrovia em Paracambi e sua incorporação ao sistema econômico escravocrata}

17 A chegada da estação ferroviária a Paracambi está ligada diretamente aos interesses dos cafeicultores do Vale do Paraíba fluminense e aos embates para o projeto de construção da Estrada de Ferro D. Pedro II.

A Estrada de Ferro D. Pedro II teve sua origem a partir da autorização imperial de junho de 1852 que concedia a uma ou mais companhias que se interessassem em fazer a 
ligação férrea entre o município da Corte (Rio de Janeiro) e as províncias de São Paulo e Minas Gerais. Embora um projeto semelhante já tivesse sido colocado em marcha por Irineu Evangelista de Souza, o futuro barão e visconde de Mauá - ligando a estação de Guia de Pacobaíba (no atual município de Magé), de onde se chegava da Corte pelo porto de Mauá, ao Vale do Paraíba, passando por Petrópolis -, o novo projeto visava atender aos interesses dos cafeicultores mais a oeste, em uma ligação feita exclusivamente por ferrovia (a primeira seria feita por via aquática, férrea, terrestre e novamente férrea). A companhia que obtivesse o privilégio ganharia a concessão da exploração da ferrovia por noventa anos, além de contar com a desapropriação de terrenos e com a cessão de terrenos devolutos para a construção do traçado da linha férrea, além da isenção de impostos para a importação de máquinas, equipamentos, carvão e trilhos. No entanto, a conclusão do empreendimento encontraria bastante dificuldade:

A proposta de construir uma estrada de ferro ligando a Corte às províncias de São Paulo e Minas Gerais, foi processo longo, moroso e marcado por uma série de tensões que envolviam desde as avultadas somas de capitais necessários, passando pelas questões de viabilidades técnico-científicas. Deve-se ainda, compor este quadro o desequilíbrio das contas do Império e sua situação política (BORGES, 2014, p.7).

19 A problemática do caso brasileiro em geral residia no fato de que não havia capital suficiente disponível porque grande parte dele estava investido em terras e escravos. Além disso, não havia uma capacidade técnica que pudesse pôr em marcha a construção de uma ferrovia de grande porte (OLIVEIRA, 2019).

20 Conforme abordamos anteriormente, o novo projeto tinha por objetivo atender aos interesses dos cafeicultores da região de Vassouras, desejosos de um meio de transporte mais eficiente e rentável do que o feito através dos tropeiros, que exigia um número significativo de escravos para a empreitada de levar o café das zonas produtoras até o porto, além daqueles utilizados no plantio do milho que serviria como alimento às mulas, algo que ficou ainda mais dispendioso a partir de 1850 quando da promulgação da Lei Eusébio de Queirós, que passara a proibir a entrada de africanos no Brasil, o que causou uma diminuição da oferta da mão de obra, justamente em uma época em que a cultura cafeeira estava em seu apogeu (OLIVEIRA, 2019; BORGES, 2014). Inicialmente, tal fato não prejudicou os fazendeiros, pois a escassez do braço escravo foi compensada pela elevação do preço e pelo aumento das exportações do café - que aumentaram consideravelmente entre os anos de 1821-30 e 1851-60, passando 3.178 sacas (de 60Kg) para 27.339 sacas - principalmente para a Europa e para os Estados Unidos. Entretanto, a partir de então, a majoração do preço da mão de obra passaria a ser uma preocupação constante (ANDRADE, 2011).

21 Segundo Ronaldo Pereira (2018), a produção de café oriunda de Vassouras e Valença descia a serra e passava pelas terras que comporiam o futuro município de Paracambi através das tropas de muares, ideia compartilhada por Maria Juvanete Pereira que afirma que o café seguia "para uma série de pequenos portos onde se localizavam as casas comissárias de café" (PEREIRA, 2005, p.3). Rômulo Andrade (2007) complementa a informação, afirmando que o município de Itaguaí [do qual Paracambi também foi desmembrado] $]^{5}$ destacava-se por ser uma das coletorias por onde o café proveniente da província do Rio de Janeiro passava para ser exportado. Mais ainda:

É importante perceber a região da Baixada de Sepetiba como um local de integração entre o porto do Rio de Janeiro e Minas Gerais, um lugar de passagem, pois estava 
no caminho de rotas comerciais. Se no início era o ouro de Minas que dinamizava a atividade comercial da região, passou-se depois à rota de alimentos e do escoamento do café do Vale do Paraíba. [...] Desta forma, as estradas vindas de Minas Gerais, São Paulo e Vale do Paraíba, encontram na antiga Vila de Iguassu e de Itaguahy os portos que levavam as mercadorias através dos rios da região até o porto do Rio de Janeiro (OLIVEIRA, 2015).

Com a mão de obra cara e o transporte dispendioso, as pressões exercidas pelos cafeicultores frente ao poder público para a construção de uma estrada de ferro eram cada vez maiores, haja vista que, no Brasil, os proprietários rurais constituíam o braço dominante da política, fazendo com que as políticas públicas do Estado imperial buscassem atender aos anseios desse segmento.

Sendo assim, em junho de 1855 as obras de construção da Estrada de Ferro D. Pedro II foram iniciadas. De acordo com o aparato técnico da época, era necessário haver uma estação a cada $20 \mathrm{~km}$ para abastecimento de água e carvão, além da supervisão e manutenção da linha. O projeto inicial previa, então, quatro estações entre a Central e Belém (atual Japeri): Três Vendas (no bairro do Engenho Novo), Cascadura, Maxambomba (atual Nova Iguaçu) e Queimados. As duas últimas, além da de Belém, receberiam gado, café e outros gêneros. Finalmente, em março de 1858, o trecho entre a estação da Corte e Queimados foi inaugurado, chegando alguns meses depois a Belém. Posteriormente, foram inaugurados a estação chamada Bifurcação (mais tarde rebatizada Guedes da Costa) e o ramal de Macacos, já em agosto de 1861, tendo atingido a cidade de Vassouras somente em dezembro de 1865 (OLIVEIRA, 2019).

Além das pressões dos cafeicultores perante o Império para que este atendesse aos seus anseios, havia uma disputa inclusive no interior desse grupo para que determinada área de plantio fosse contemplada com as benesses do poder público. Sendo assim, a construção de uma estação ferroviária não fugiu a este embate entre os produtores de café, pois a estação de Macacos (atual Paracambi) foi fruto das pressões dos cafeicultores de Vassouras e, por sua vez, fruto também de uma disputa de forças entre duas famílias importantes do Vale do Paraíba fluminense: os Teixeira Leite, que desejavam que a extensão da linha férrea seguisse pela localidade de Morro Azul; e os Faro, cujo desejo foi atendido, sendo inaugurado o ramal de Macacos, em 01 de agosto de 1861 para o trânsito de passageiros e em 07 de setembro para o transporte de mercadorias (FIGUEIRA, 1908). Para que não haja confusão entre nomes, é importante ressaltar aqui que a estação inaugurada com o nome de Macacos passou a se chamar Paracamby (segundo grafia da época) em 1903 (FIGUEIRA, 1908) e, já na década de 1940, teve seu nome mudado para Tairetá, retomando novamente o nome de Paracambi quando da emancipação do município. ${ }^{6}$

Apesar de o projeto ter sido autorizado pelo governo imperial, o ramal de Macacos não pertenceu à Companhia Estrada de Ferro D. Pedro II, ficando parte de sua construção a cargo do capital empregado pelos proprietários das terras:

Este ramal, cuja construcção, a principio, se abandonara, porque o Governo não autorisara o emprego de capital garantido, foi depois concluido quasi todo a expensas dos proprietarios da fazenda dos Macacos, concorrendo apenas a Companhia com os trilhos e o edifício de madeira mandado vir dos Estados Unidos, tudo na importancia de 56:878\$169, e tocando aos proprietarios metade da renda bruta do ramal, para premio e amortisação de seus capitaes (FIGUEIRA, 1908, p.40, com ortografia da época). 
julho de 1865, o governo imperial, por meio do contrato celebrado com os proprietários das terras, obrigava-se a manter o ramal pelo período que a própria Estrada de Ferro D. Pedro II existisse, concedendo também livre passagem aos proprietários do ramal em todos os trens da companhia. Entretanto, de acordo com Figueira (1908), tal contrato não durou por muito tempo, haja vista que, um decreto de setembro de 1865 passava o ramal de Macacos para o domínio estatal por cessão de seus proprietários.

Não obstante o gasto que os proprietários das terras tiveram que dispensar na construção do ramal, a chegada da ferrovia ao povoado de Macacos representava uma nova dinâmica na atividade cafeeira, bem como a possibilidade do aumento dos lucros dos grandes proprietários rurais.

O uso do meio ferroviário para o escoamento das sacas de café tornou obsoleto o transporte realizado por muares. Dessa forma, as ferrovias apresentaram-se como uma opção mais vantajosa dentro da lógica capitalista, reduzindo o tempo de transporte da mercadoria e aumentando o volume transportando, influindo na taxa de lucro do investidor e no aumento da produção (OLIVEIRA, 2019, p.30).

Sendo assim, a construção da estação de Macacos estava inserida em uma lógica geral da implantação das ferrovias no Brasil durante o século XIX que serviam como escoadouros da produção agrícola do país para os portos que, a partir destes, atingiria vários centros urbanos espalhados pelo mundo. Logo, de acordo com Oliveira (2019), a malha ferroviária brasileira apresentava como objetivo principal fazer a interligação entre as áreas produtoras e aquelas que comercializariam a produção, aumentando-se sua expansão à medida que aumentavam a produção e a demanda externa pelo café. Além disso, a malha ferroviária ia aumentando de tamanho quanto mais as áreas produtoras de café se expandiam, principalmente na direção das antigas províncias de São Paulo e Minas Gerais. Portanto, a expansão do espaço econômico motivado pelo aumento das áreas produtoras de café e a expansão das ferrovias estavam diretamente atreladas.

[...] o crescimento da infra-estrutura ferroviária ao longo do século XIX provocou a expansão do espaço econômico. As descontinuidades foram paulatinamente perdendo o caráter de barreiras naturais para assumir a expressão de vazios econômicos, isto é, espaços com baixa densidade e diversidade de atividades e precariamente inseridos nas rotas mais valorizadas do comércio internacional (PIRES DO RIO, 2012, p.173).

Contudo, podemos pensar que embora o povoado de Macacos, a partir de 1861, contasse com um dos símbolos da Revolução Industrial (a locomotiva a vapor), esta estava a serviço de uma relação cujo acúmulo de capital não residia na produção industrial, mas servia sobremaneira para a manutenção da produção agrícola pautada na mão de obra escrava. Mais ainda, a presença de uma inovação tecnológica como a ferrovia criou uma nova forma de organização do espaço no povoado de Macacos, haja vista que, além de contribuir para o seu aumento populacional (que se concentrou no entorno da estação ferroviária), foi um fator determinante para a instalação da Companhia Têxtil Brasil Industrial alguns anos mais tarde.

Portanto, podemos afirmar que o então povoado de Macacos passava a contar com um fixo que era típico do meio técnico ou maquínico, uma fase intermediária entre o meio natural e o meio técnico-científico-informacional, tal qual a definição dada por Milton Santos $(2004 ; 1996)$. Nesta fase, o espaço se torna um espaço mecanizado, não sendo apenas formado por objetos culturais, e sim por objetos culturais e técnicos ao mesmo 
tempo. Os objetos naturais que antes formavam a natureza selvagem, então, ao longo do tempo cedem lugar aos objetos fabricados, técnicos.

Através da presença desses objetos técnicos: hidroelétricas, fábricas, fazendas modernas, portos, estradas de rodagem, estradas de ferro, cidades, o espaço é marcado por esses acréscimos, que lhe dão um conteúdo extremamente técnico (SANTOS, 2004; 1996, p.63).

31 Tomando como base a definição de fixos e fluxos de Milton Santos, para quem os fixos nada mais são do que os próprios instrumentos de trabalho e as forças produtivas, enquanto os fluxos "são o movimento, a circulação e assim eles nos dão também a explicação dos fenômenos da distribuição e do consumo" (SANTOS, 2012; 1988, p.86). Sendo assim, esse fixo que é a estação ferroviária de Macacos foi criado com a intencionalidade de atender as necessidades dos produtores de café da região de Vassouras, inserindo-a em um circuito econômico, gerando, por sua vez, fluxos (de pessoas, de capital, de informações, etc.) que também chegam a esse fixo. Por consequência, o fixo (a estação ferroviária) é, ao mesmo tempo, um objeto técnico e um objeto social.

32 A paisagem apresenta a marca das mudanças de uma sociedade ao longo do tempo, com seus acréscimos e subtrações, sendo, então, o resultado de uma acumulação de tempos (SANTOS, 2004; 1982), composta de atualidades de hoje e do passado, "uma espécie de marca da história do trabalho, das técnicas" (SANTOS, 2012; 1988, p.74). A chegada da estação ferroviária a Macacos significou, portanto, uma alteração da paisagem, uma marca do progresso técnico daquela época e ainda presente na paisagem do município de Paracambi, embora com um uso diferente daquele pensado originalmente quando das discussões para sua instalação no século XIX.

A eletrificação da estrada de ferro, em 1949, tornou as viagens até a Baixada Fluminense e ao Rio de Janeiro mais rápidas, favorecendo a ocupação do município mediante loteamentos populares e expandindo a área urbana, incorporando Paracambi a uma dinâmica metropolitana. Com o fechamento da Companhia Têxtil Brasil Industrial e a decadência da indústria têxtil no município, Paracambi passou a depender economicamente das cidades no seu entorno, principalmente Nova Iguaçu e Itaguaí (PEREIRA, 2018). A ferrovia, então, passou a ter um papel não mais como um escoadouro de produtos agrícolas ou têxteis, mas agora como meio de transporte para os trabalhadores que se deslocam diariamente para seus empregos ou em busca deles.

\section{Crise do café e a Companhia Têxtil Brasil Industrial}

Embora o café do Vale do Paraíba fluminense tenha atingido seu nível máximo de produção em 1882, no ano seguinte já havia sido igualado pela província de São Paulo, sendo ultrapassado três anos depois (PEREIRA, 2005, p.5). Entretanto, o período que é considerado como o do auge do café foi aquele entre as décadas de 1850-60, um período que coincide com as pressões dos cafeicultores para a construção de uma estrada de ferro que escoasse a produção cafeeira das fazendas até o porto do Rio de Janeiro, contando com uma estação que atenderia seus anseios, a de Macacos, inaugurada, conforme já abordamos, em agosto de 1861.

Contudo, a partir da década de 1870, a produtividade das fazendas de café na província do Rio de Janeiro já mostrava sinais de queda. Muitas foram as razões que levaram à derrocada da lavoura cafeeira fluminense, entre fatores ambientais e econômicos. No 
caso do Vale do Paraíba fluminense, segundo os próprios cafeicultores, as principais razões para o declino eram:

a falta de mão de obra escrava, os altos custos para aquisição de modernos equipamentos de processamento de café, a dificuldade para obtenção de créditos agrícolas a baixos custos, as secas e as pragas nos cafezais. Muitos deles se recusavam a aceitar que suas práticas agrícolas adotadas não eram as mais adequadas. $O$ esgotamento do solo da região e os cafeeiros envelhecidos também tiveram grande influência na decadência da cafeicultura do Vale do Paraíba (STEIN apud ANDRADE, 2011, p.35).

36 Nesse sentido, Maria Juvanete Pereira (2005) aponta que a vida útil da plantação de café se dava até os 10 anos, sendo considerada velha em torno dos 25 anos. Além disso, a falta de investimentos em técnicas e aparatos mais avançados fizeram com que o solo se tornasse cada vez mais pobre, levando a uma busca cada vez mais incessante por solos virgens que, por sua vez, tiveram seus preços aumentados. Aliado aos danos ambientais que levaram à queda da produtividade, os grandes produtores estavam endividados, pois, no momento de prosperidade foram obrigados a recorrer a empréstimos bancários para adquirir a mão de obra escrava que já se configurava escassa, o que aumentou seu preço. Com a queda da produtividade, a capacidade desses cafeicultores em honrar suas dívidas foi sensivelmente diminuída. Mais ainda, de acordo com Oliveira (2015), a crise atingiu de maneira muito mais direta os "barões do café" porque estes, ao contrário dos pequenos proprietários, não diversificaram sua produção naquele momento, tampouco acreditavam que suas fazendas chegassem à falência.

Embora não tenhamos dados específicos sobre como o povoado de Macacos foi atingido pela crise do café, podemos supor que os fluxos de pessoas e de mercadorias foram diminuindo sensivelmente. $\mathrm{E}$ é justamente neste contexto da crise do café no Vale do Paraíba fluminense que vai se efetuar a instalação da Companhia Têxtil Brasil Industrial.

Nas terras da despovoada fazenda dos Macacos iniciaram-se as obras, em setembro de 1870, da Companhia Têxtil Brasil Industrial, cujo objetivo era a fabricação de tecidos de algodão. Alguns fatores podem explicar a escolha de um local ainda pouco populoso, cuja atividade econômica baseava-se na agricultura e na força de trabalho escrava, para a instalação de uma fábrica de tecidos de tamanho porte. Segundo Gabriela Souza (2016), o fim da Guerra de Secessão nos Estados Unidos e o retorno de suas exportações de algodão, levaram a uma queda no preço deste item, fazendo com que houvesse uma crise na produção brasileira, barateando o algodão. Por outro lado, a queda do preço do algodão no Brasil fez com que houvesse uma espécie de renascimento das fábricas de tecidos. Além disso, o fim do tráfico negreiro, em 1850, contribuiu para o acúmulo de capital que passou a estar disponível para investimentos em outros empreendimentos, beneficiando, assim, o comércio, os bancos e a indústrias têxteis. Voltando especificamente a Paracambi (ou mais precisamente à antiga Macacos), já em 1867, o governo imperial emitiu uma autorização para a construção de uma fábrica têxtil nas terras da Fazenda do Ribeirão dos Macacos, porém, o projeto sequer foi iniciado. Ficaria a cargo do estadunidense Willian S. Elisson, engenheiro da Estrada de Ferro D. Pedro II e que possuía experiência na construção de fábricas, iniciar as obras da Companhia. Entre os fatores escolhidos para a instalação da fábrica naquele local estavam, ainda de acordo com Sousa, a quantidade e a altura das águas dos rios presentes ali que serviriam como propulsores do maquinário. Além dessa vantagem, a presença da linha férrea foi também determinante, pois através dela chegaria tudo o que era necessário 
para a efetivação da obra, bem como, posteriormente, escoar-se-ia a produção fabril. De acordo com Furtado (2018), o segundo motivo foi o principal em relação à escolha por Paracambi para que um empreendimento de tamanha monta fosse posto em marcha, haja vista que seus proprietários poderiam contar com o favorecimento do governo imperial no que concerne à gratuidade do transporte pela ferrovia tanto do material necessário à sua construção quanto de sua produção futura, algo que foi confirmado pelo decreto assinado pela princesa Isabel, então regente, em 06 de setembro de 1871, que confirmava tal gratuidade, além de aprovar o estatuto e o funcionamento da Companhia Têxtil Brasil Industrial.

O projeto da Companhia previa a construção de um prédio de três andares com pedras rústicas e tijolos aparentes, seguindo o modelo das fábricas inglesas, e que abrigariam cerca de quatrocentos teares e vinte e quatro mil fusos, todos importados de Manchester e Liverpool. o projeto também previa a construção de um aparelho para a contenção de incêndios e de uma linha férrea de cerca de um quilômetro de comprimento que ligaria os portões da fábrica à estação de Macacos para facilitar o escoamento da produção e a chegada e saída dos trabalhadores ao prédio (PEREIRA, 2018).

No entanto, é interessante observarmos, em concordância com Furtado (2018), que ainda que se configurasse como um projeto moderno que representaria um olhar para o futuro, um novo fixo com novos fluxos, a Companhia Têxtil Brasil Industrial foi instalada em um momento e em um espaço extremamente arraigados à dinâmica econômica agrícola baseada na mão de obra escrava.

A especificidade desse projeto, então, assentava-se nessa relação de complementaridade entre elementos novos e tradicionais; na conjugação de práticas ligadas ao modelo agrário e ao modelo de industrialização importado da Inglaterra (FURTADO, 2018, p.3).

41 A presença da Companhia Têxtil Brasil Industrial - cujo funcionamento deu-se efetivamente a partir de 1874 - aliada à Estrada de Ferro D. Pedro II possibilitou o progresso e o povoamento local. Entretanto, ao longo do espaço de tempo entre a sua idealização e a sua efetivação na paisagem das terras da antiga Fazenda dos Macacos, a companhia apresentou alguns problemas que trouxeram dificuldades à sua manutenção, tais como, a exaustão do capital, com o transporte, com o abastecimento de algodão e com a mão de obra. Durante o período, os proprietários da fábrica tiveram que recorrer a empréstimos para poderem dar prosseguimento ao projeto, chegando a solicitar ajuda financeira do Império, que foi negado. Além disso, o fato de terem a garantia da gratuidade do transporte pela linha férrea, o que seria uma vantagem, acabou muitas vezes atrapalhando porque as entregas eram preteridas pelos administradores da ferrovia. Porém, a grande problemática era a ausência de mão de obra qualificada para compor a força de trabalho da fábrica. Como estava fixada em um local de base econômica escravista, uma parte considerável da mão de obra era composta por escravos, cada vez mais escassa e cara e comprometida quase que exclusivamente com a produção cafeeira, ainda que a companhia tenha realizado a contratação de mão de obra imigrante. Entretanto, os trabalhadores da companhia eram compostos em grande parte por mulheres e crianças para quem eram pagos baixos salários sob a lógica do pensamento da época de que havia uma aura de benevolência empregar crianças e pessoas livres pobres (SOUZA, 2016). 
42 Em se tratando de uma sociedade ainda escravista, as relações de trabalho entre patrões e empregados não estava distante daquela estabelecida entre senhores e escravos. No caso da Companhia Têxtil Brasil Industrial, seu projeto foi idealizado e construído por uma elite imperial ligada aos negócios do café, não sendo surpreendente o fato de que seus proprietários passaram a ocupar a casa-grande da antiga fazenda, enquanto os operários ocuparam a senzala (FURTADO, 2018; SOUZA, 2016).

[...] era clara a atração exercida entre os trabalhadores da região, escravizados ou não, pelo novo empreendimento fabril. Entretanto, se era esperada uma separação legal dos senhores, esses homens e mulheres, livres ou alforriados, ao procurarem outra atividade que não fosse agrícola, se deparavam com semelhanças e continuidades entre esses mundos que compartilhavam análogas práticas de dominação efetivas e simbólicas (FURTADO, 2018, p.5).

Sendo assim, estava claramente presente uma simbiose entre o trabalho escravo e o trabalho livre e assalariado no interior do espaço fabril da companhia, onde as relações patriarcais que marcaram as relações do trabalho escravo até o momento da abolição se mantinham.

A fábrica criou, além dos empregos, uma rede assistencialista que contava com diversos "braços". o primeiro deles e, sem dúvida, um dos mais importantes foi a construção da vila operária, local destinado a ser moradia dos trabalhadores da companhia e de seus familiares, legitimando, de acordo com Pereira (2018), o poder patronal sobre o operariado. Além disso, tal operariado estava sob constante vigilância dos patrões, haja vista que, a vila operária ladeava a avenida que dava acesso aos portões da fábrica. Tal vigilância gerava apreensão nos operários, reforçando o poder dos patrões, pois como só era possível ocupar as casas da vila operária sendo funcionário da fábrica, perder o emprego significava perder também a moradia. A rede assistencialista que solidificava o controle patronal estava presente também nos locais onde se promoviam festividades, como a capela de Nossa Senhora da Conceição e o Clube Cassino Social, além de uma escola anteriormente destinada à qualificação da mão de obra, e que passou a funcionar como uma escola noturna para os menores que depois transformou-se em uma escola regular para os demais funcionários e de um cemitério construído pela fábrica. Por fim, a fundação de um clube destinado à prática do futebol (o Brasil Industrial Futebol Clube) destinava-se a manter distraídos tanto o operário quanto àqueles que estariam lá para assistir as partidas.

Motivar os operários a jogar bola era, acima de tudo, uma forma de distração desse operário-atleta, pois isso de certa forma desfocava a atenção do operário para as questões de lutas de classes. Aos olhos do patrão, também poderia ser usado como garoto propaganda dos produtos e da própria companhia (PEREIRA, 2018, p.55).

Ainda segundo o autor supracitado, a decadência da Companhia Têxtil Brasil Industrial que culminou em seu fechamento em meados da década de 1990, começou na década de 1950 quando os novos administradores implantaram mudanças que dissolveram a estrutura iniciada ainda no século XIX, tais como a venda das casas da vila operária, do Clube Cassino e de outros terrenos pertencentes à fábrica. A emancipação do município, em 1960, também criou uma ruptura nas relações de poder local. Se antes era a fábrica que comandava a vida social de Paracambi através das relações patriarcais, tal poder passava às mãos da recém-criada administração pública.

47 Com o encerramento das atividades da Companhia em 1996, o complexo fabril, alguns anos depois, foi adquirido pela prefeitura de Paracambi, que o denominou de Fábrica do 
Conhecimento, um complexo educacional e cultural onde se fazem presentes a Companhia Municipal de Balé, o planetário, um núcleo da Escola de Música Villa-Lobos, além de um campus do Instituto Federal Fluminense (IFRJ), da Fundação de Apoio à Escola Técnica (FAETEC) e um polo do Centro de Educação à Distância do Rio de Janeiro (Cederj).

\section{Conclusão}

Ao longo deste breve escrito, pudemos perceber que a construção de uma estação ferroviária na paisagem de um pequeno povoado da então província do Rio de Janeiro foi fruto de intensas negociações e pressões de importantes proprietários rurais do Vale do Paraíba fluminense que objetivavam um meio mais barato, mais seguro e que propiciasse maior lucro aos grandes cafeicultores, inserindo-a no modelo econômico escravocrata.

Sendo assim, pudemos constatar que a presença da ferrovia, mesmo sendo um dos símbolos da Revolução Industrial, foi fundamental para a manutenção do modelo econômico pautado na grande lavoura e no braço escravo no Vale do Paraíba fluminense, não obstante a escassez de mão de obra conflagrada a partir de 1850 mediante a proibição do tráfico de escravos para o Brasil.

Com o passar do tempo e a crise do café que se abateu sobre a província, a estação ferroviária do então povoado de Macacos foi fundamental para que este fosse escolhido para a execução de uma obra de grande envergadura tal qual a da Companhia Têxtil Brasil Industrial, incorporando, ainda que de maneira bastante incipiente, a localidade a uma economia industrial, embora, quando da inauguração da fábrica, ambos os modelos ainda convivessem.

51 A partir da emancipação do município de Paracambi e a crise que assolou a Companhia Têxtil Brasil Industrial, culminando em seu fechamento, a estação ferroviária passou a se dedicar exclusivamente ao transporte diário de passageiros para os demais municípios da Baixada Fluminense e também para a capital, inserindo Paracambi na dinâmica econômica da Região Metropolitana, sendo administrada, via concessão pública, pela Supervia S.A que realiza, segundo (2017) relatório realizado pela Agência Reguladora de Serviços Públicos (Agetransp) ${ }^{7}$, cerca de 60 viagens diárias (em dias úteis) entre Paracambi e Japeri, de onde se deve fazer baldeação para a composição com destino a Central do Brasil, conforme pôde ser visto no diagrama de rede exposto neste texto.

\section{BIBLIOGRAFIA}

ANDRADE, João Paulo Motta de. O desenvolvimento da atividade cafeeira no Vale do Paraíba Fluminense de 1850 a 1888. Rio de Janeiro, Monografia de Bacharelado em Economia. Instituto de Economia. Universidade Federal do Rio de Janeiro, 47p., 2011. 
ANDRADE, Rômulo Garcia de. Aspectos demográficos da escravidão em uma freguesia da Baixada de Sepetiba, na província do Rio de Janeiro: N. Sra. Da Conceição do Bananal, 1847-1872. In: VII Congresso Brasileiro de História Econômica, Aracaju, p.1-16, 2007.

BORGES, Magno Fonseca. A Companhia Estrada de Ferro D. Pedro II: o desafio da serra do mar (1850-1865). In: XVI Encontro Regional de História da Anpuh-Rio, Rio de Janeiro, p.1-15, 2014.

FIGUEIRA, Manuel Fernandes. Memória histórica da Estrada de Ferro Central do Brasil. Rio de Janeiro: Imprensa Nacional, 960 p., 1908.

FURTADO, Cristiane Silva. A gigante Brasil Industrial: herança e modernidade no Vale Paraíba fluminense; a fábrica Paracambi na segunda metade do século XIX. Espaço e Economia, n.12, pp. $1-15,2018$.

OLIVEIRA, Leandro Mendes. Políticas estatais e meios de transporte no Brasil: Estudo de caso sobre o desmantelamento do trecho ferroviário da Linha Auxiliar Japeri - Miguel Pereira (1957-1980). Seropédica, Dissertação de Mestrado em História. Programa de Pós-Graduação em História. Universidade Federal Rural do Rio de Janeiro, 175p., 2019.

OLIVEIRA, Max Fabiano Rodrigues de. Do café à policultura: fazendeiros, lavradores foreiros e as transformações na estrutura fundiária de São Francisco Xavier de Itaguaí (1850-1900).

Seropédica, Dissertação de Mestrado em História. Programa de Pós-Graduação em História. Universidade Federal Rural do Rio de Janeiro, 118p., 2015.

PEREIRA, Maria Juvanete Ferreira da Cunha. História ambiental do café no Rio de Janeiro - século XIX: a transformação do capital natural e uma análise de desenvolvimento sustentável. In: XXIII Simpósio Nacional de História, Londrina, p.1-8, 2005.

PEREIRA, Ronaldo Vicente. Paracambi industrial: uma proposta de roteiro cultural. Rio de Janeiro, Dissertação de Mestrado em Bens culturais e projetos sociais. Programa de PósGraduação em História, política e bens culturais. Fundação Getúlio Vargas, 123p., 2018.

PIRES DO RIO, Gisela. A espacialidade da economia: superfícies, fluxos e redes. In: CASTRO, Iná Elias; GOMES, Paulo Cesar da Costa; CORRÊA, Roberto Lobato (org.). Olhares geográficos: modos de ver e viver o espaço. Rio de Janeiro: Bertrand Brasil, pp. 155-187, 2012.

SANTOS, Milton. Metamorfoses do espaço habitado: fundamentos teóricos e metodológicos da Geografia. 6.ed. São Paulo: Edusp, 132p., 2012 (1988).

. A natureza do espaço: técnica e tempo, razão e emoção. 4.ed. São Paulo: Edusp, 384p., 2004 (1996).

Pensando o espaço do homem. 5.ed. São Paulo: Edusp, 90p., 2004 (1982).

SOUZA, Gabriela Gomes Rodrigues de. A indústria têxtil na crise do Império: o caso da Companhia Têxtil Brasil Industrial. In: XVII Encontro Regional de História da Anpuh-Rio, Nova Iguaçu, p.1-8, 2016.

\section{NOTAS}

1. Disponível em: https://cidades.ibge.gov.br/brasil/rj/paracambi/panorama. Acesso em: 26 maio 2020.

2. Disponível em: http://fnembrasil.org/regiao-metropolitana-do-rio-de-janeiro-rj/. Acesso em: 21 jul. 2020. 
3. Disponível em: http://ferroviasdobrasileregioes.blogspot.com/2013/08/a-estacaode-macacos-1-inaugurada-em.html. Acesso em: 21 jul. 2020.

4. Disponível em: http://www.estacoesferroviarias.com.br/efcb_rj_linha_centro/ mapa_linhacentro_rj.htm. Acesso em: 21 jul. 2020.

5. Grifo nosso.

6. Informação obtida em: www.estacoesferroviarias.com.br/efcb_rj_linha_centro/ paracambi.htm. Acesso em: 28 maio 2020.

7. Disponível em: http://www.agetransp.rj.gov.br/documents/10181/900621/ Relat\%C3\%B3rio+Mensal+de+Atividades+CATRA+de+Agosto+de+2017/587aadf5-562b-47ff-9112-802c70243681. Acesso em: jun.2020.

\section{RESUMOS}

O presente artigo busca demonstrar como a chegada da ferrovia a Paracambi veio no bojo das discussões e pressões exercidas pelos grandes cafeicultores da região do Vale do Paraíba fluminense, que buscavam um meio mais rápido, eficiente e lucrativo para escoar a sua produção. Logo, mesmo sendo um dos símbolos da Revolução Industrial, a chegada da ferrovia veio atender ao modelo econômico baseado na grande lavoura e no trabalho escravo. Além dessa análise, buscamos compreender como a existência da ferrovia foi fundamental para a escolha de Paracambi para a instalação de um grande empreendimento fabril mesmo em um momento em que predominava o modelo agrícola e escravocrata, significando a presença de um incipiente modelo econômico urbano-industrial, ainda que isto não rompesse definitivamente com o modelo anterior.

El propósito de este artículo es demostrar como la llegada del ferrocarril a Paracambi ha sido una consequéncia de las discusiones y presiones ejercidas por los grandes cafeteros de la región del Valle del Río Paraíba en Río de Janeiro, que han buscado una forma más rápida, eficiente y rentable para drenar su producción. Entonces, aunque sea uno de los símbolos de la Revolución Industrial, la llegada del ferrocarril ha respondido a un modelo económico basado en el grande cultivo y en el brazo esclavo. Además de este análisis, hemos buscado comprender cómo la existéncia del ferrocarril ha sido fundamental para la elección de Paracambi para la instalación de una gran compañía manufacturera, incluso en um momento en que predominaba el modelo agrícola y de esclavitud, lo que significaba la presencia de un incipiente modelo económico urbano-industrial, aunque esto no ha rompido permanentemente con el modelo anterior.

This article has the purpose to demonstrate how the railway in Paracambi has been a consequence of discussions and pressures exerted by coffee producers of Paraíba River Valley in Rio de Janeiro, who have been searched for a faster, more efficient and more rentable way to drain their production. So, even though it was one of the symbols of the Industrial Revolution, the arrival of the railway has satisfied an economic model based on the plantation and slavery. In addition to this analysis, we have sought to comprehend how the railway existence was fundamental to the choice of Paracambi for the installation of a big textile industry in a moment which the agricultural model and the slavery have predominated, signifying the presence of an 
incipient urban-industrial economic model, although it has not definitively broken with the previous model.

Cet article veut demonstrer comment l'arrive du chemin de fer à Paracambi a eté une consequence des discussions et des pressions exercées pour les caféiculteurs de la region du Vallée du Fleuve Paraíba à Rio de Janeiro, qui cherchaient un moyen plus rapide, efficient et profitable pour drainer sa production. Donc, même comme un des symboles de la Révolution Industrielle, l'arrivée de la gare a satisfait un modèle économique basé en la grande culture et en l'esclavage. En plus de cette analyse, nous avons cherché comprendre comme l'existence du chemin de fer a eté fondamental au choix de Paracambi pour l'installation d'une enteprise industrielle même à une époque où prévalait le modèle agricole et esclavagiste, signifiant la présence d'un modèle urbain-industriel naissant, bien que ce n'ai pas definitivement romput avec le modèle précédent.

\section{ÍNDICE}

Mots-clés: Paracambi; chemin de fer; modèle économique; industrie textile.

Keywords: Paracambi; railway; economic model; textile industry.

Palabras claves: Paracambi; ferrocarril; modelo económico; industria textil.

Palavras-chave: Paracambi; ferrovia; modelo econômico; indústria têxtil.

\section{AUTOR}

\section{ZILMAR LUIZ DOS REIS AGOSTINHO}

Mestre em História Social (PPGHS/Uerj), Licenciado em Geografia (Uerj/FFP) e Doutorando do Programa de Pós-Graduação em História (PPHR) da Universidade Federal Rural do Rio de Janeiro (UFRRJ). Licenciado em Geografia (Uerj/FFP). 